\title{
New Product Development Procedure Reengineering Based on the Lean Theory
}

\author{
WANG Shuang ${ }^{1, a}$, LIU Xiaolin ${ }^{2,}$, SHI Jiangang ${ }^{3}$ \\ ${ }^{1,2,3}$ Sichuan Solid Circuit Research Institute, Chongqing, China \\ a wangshuangcarol@163.com
}

Keywords: lean theory, product development, business procedure reengineering

\begin{abstract}
The pace of building an innovative country has been faster in our country, and the IC R\&D nationalization is more and more argent. In this environment, this article makes an exploratory study about the new product development process based on lean management. Through the analysis of the status of IC R\&D, the article introduces lean management into new product development process, combining the analysis of practical problems in the process of new product development, and suggests the methods of new product development procedure reengineering based on lean management thinking to achieve business continuous improvement and value added .
\end{abstract}

\section{Introduction}

With the rapid development of China's electronic information industry and electronic components localization, the domestic IC R\&D enterprises are facing unprecedented opportunities and challenges. The opportunity is that companies can expand the market further. However, they face enormous challenges, such as how to meet different customers' needs for different products with faster delivery, higher quality, lower costs and better services. And they should increase competitiveness gradually in cost, technology, service and other aspects, in order to bring customers more value and better service, enabling businesses in a more favorable position in the market competition, while maintaining the sustainable development of enterprises. The enterprises must solve these problems.

\section{The Status of New IC Product Development}

The unbalance of development cycle, development costs and quality requirements in IC product $\mathrm{R} \& \mathrm{D}$ becomes a bottleneck restricting the development of domestic enterprises.

The enterprises are required to shorten the product development cycle. To meet the increasing demand of domestic and external competitive pressures, market opportunities, the enterprises must accelerate new product development continuously.

Development costs and product costs continue to increase. On the one hand, high product reliability requirements continue to be increased. On the other hand, the rising raw material prices make the product material costs and production costs increased. Meanwhile, the price advantage of the products has become an essential competitive advantage. We must continue to meet customer price requirements.

New product features escalating is demanded. Compensating and enhancing the performance of existing products to meet user needs better, new products often use new technologies, new processes, new materials to continuously improve product functional requirements, which makes the product verification cycle extension and increase $R \& D$ costs.

\section{Overview of Lean thinking and Process reengineering}

Overview of Lean Thinking. The concept of lean management thinking is from the time production concept of Toyota. Its core business is to eliminate the waste in all aspects of manufacturing 
completely. Currently, lean management thinking has been used from the production system to the rest of the business management activities.

The lean management thinking requires companies must use "lean" in all activities. Its core idea is to create the greatest value with a minimum investment of resources. It seeks a balance among cost, quality control and assurance of progress, so as to enhance customer satisfaction. Its goal is to provide customers with satisfied products and services with a minimum waste.

Five basic principles of lean management thinking:

Identify Customers and Specify Value -Usually only a small part of the total time and effort in the organization adds value for the end customer. By clearly defining value for a specific product or service from the end customer's perspective, all the non-value activities or waste can be targeted for removal.

Identify and Map the Value Stream -The value stream is the entire set of activities across all parts of the organization involved in jointly delivering the product or service. This represents the end-to-end process that delivers the value to the customer. Once you understand what your customer wants the next step is to identify how you are delivering (or not) that to them.

Create Flow by Eliminating Waste-Typically when you first map the value stream, you may find that only some activities add value, this can raise more in a service environment. Eliminating this waste ensures that your product or service "flows" to the customer without any interruption, detour or waiting.

Respond to Customer Pull- This is about understanding the customer demand on your service and then creating your process to respond to this. That means you produce only what the customer wants when the customer wants it.

Pursue Perfection -Creating flow and pull starts with radically reorganizing individual process steps, but the gains become truly significant as the entire steps link together. As this happens more and more layers of waste become visible and the process continues towards the theoretical end point of perfection, where every asset and every action adds value for the end customer.

Significance of Process Reengineering Based on Lean Thinking. The process is divided into business processes and management processes. Generally, business process refers to workflow, which is to serve customers and the market in everyday manufacturing processes. It reflects the market-orientation, customer-centric. Management process is the interaction among the various management tasks, which supports business processes, mainly for internal management, reflecting the focus on efficiency. New product development process belongs to the business process. BPR aims that the enterprises can deliver faster and better products and provide better services.

The IC R\&D enterprises' major problems in practice are as below.

First, in the implementation of new product development and design, product design and development cycle are too long, the quality is still relatively weak, and new product development costs continue to increase and so on.

Secondly, the demand for new product development and design is not in accordance with market trends and customer needs, and the market research and analysis of the technical feasibility of new products is not in time. Thus it is unable to meet schedule or performance requirements.

It is because of the new product development cycle lags far behind the demand characteristics of the product, the process has become increasingly unable to meet the current rapidly changing external environment and continuously expand business development needs. Lean thinking can achieve a breakthrough. It can change the business model, and increase overall efficiency. Lean thinking-based process reengineering will help companies focus from product supply to new technology pulling customers' needs. It makes the enterprises shift from the traditional mode production to performance orientation.

\section{Manners of New Product Development Procedure Reengineering Based on Lean Theory}

New product development process reengineering of IC R\&D is a large and complex systematic engineering. The project implementation process involves multi-sector and multi-level activities. And how to implement new product development process based on lean thinking? 
Determine the Goals and Define the Value. BPR is intended to achieve customer needs through process optimization, thereby to support long-term development of enterprises. It is to find new product development process with efficient operation. It can reduce new product development costs effectively, shorten the development cycle of new products, upgrade the product features and improve performance to create core competencies which is difficult to be copied by competitors, enhance customer satisfaction degrees, and consolidate and enhance the company's position in the industry.

Identify the Value Stream and Eliminate Waste. To achieve the design goal at the target cost requirements with innovation, we will take measures to control the cost of new product development process. It is necessary to introduce lean development costs to the various stages of product design and development, to make the whole process control and achieve lean.

New product design and development process is broadly divided into feasibility assessment, design and implementation, test and verification, design stereotypes, etc., and all these processes are the value stream of product realization. So, we will look for the waste in these processes.

Usually, the following phenomena exist during the new product design process:

Information islands, the tacit knowledge management is not effective;

Low efficiency caused by waste;

Verification lead to excessive waste of development costs;

Over quality requirements for the sample, high performance standards, bringing the overflow;

Excessive changes, resulting in waste costs.

All these wastes are the opportunity to improve the value of enterprise. The enterprises should collect experience in time, eliminate information islands, summary tacit knowledge to be managed, form design standards and platforms, and constantly update and share these by information technology, so that the designers can reduce the information collection time, avoid information loss caused due to changes in personnel, thereby improving the efficiency in design and development. Meanwhile, the designers should be trained, including understanding the corporate culture, learning quality system knowledge, process development methods and other aspects, in order to make the new designers integrate as soon as possible and gradually grown-up. Then the knowledge can be passed and the professionals can be sustainable developed.

Maintain the Flow of the Value. Information transmission is most important during new product development process additional to the product itself. In order to ensure fast and accurate flow of value and continue to add value, the enterprise must eliminate waste in all possible aspects.

In order to eliminate the waste caused by improper management in supply chain management, internal operations and other aspects, we must address the following issues.

Knowledge Sharing - In the new product development process, it is important to seize all the details of best practices, skills and processes to form the knowledge prototypes, establish standards and platform sharing between different teams so that engineers can learn in the early stages of project development. It can quickly enhance human resource capacity, improve team capabilities and create a learning organization to accelerate project development progress.

Implementation of Standards Management - The file formats, parts size, version should be unified and solidified by templates and standardization to reduce waste because of lack of basic elements of file or standard operating procedures. But not all processes are required to be standardized on the same level. Corresponding to different stages of product design and development, the standards should be from rigorous to flexible.

Enterprises can also handle the technical assessment by IT platform. It can reduce or merge nodes and show different template styles in order to increase the efficiency.

Establish Internal Trust - In the new product development process, there are always a lot of internal or external files, assessment and approval, but these processes are often very complicated. If you wait until the assessment is completed before work, that is a waste of resources and reduce efficiency and greatly increase internal friction. In the project implementation process, the enterprises should encourage personal integrity and responsibility. The office politics is a great waste and it is to 
increase management costs, so the enterprise should establish basic trust. Lean document approval should be: If the signature is not required, this step is omitted.

Stimulate Demand from Internal Downstream Customers. In the new product development process, the tasks within the enterprise have the corresponding clients. The last step should consider the demands of the next step fully, to create relevant internal customer satisfaction.

Traditional project management is a passive model, like "sandbags-throwing". Without some convergence, there will be a gap between independent tasks definitely. At last, rework, errors and omissions will be arisen. Lean project management requires the person responsible for each task and the clients of the task collaborate to determine the form, content and expected results jointly. They work together and promote each other.

Continuous Improvement. To be developed sustainably, the enterprise must continue to seek the method which can increase value, reduce the cost, and eliminate any waste. In the new product development process, it is necessary to focus on the ongoing value inspection, continuous improvement processes and organizational structures, and evaluate the effect of improving. Also the successful experience through continuous improvement in product development and project management can be popularized to other aspects of corporate, making business processes and management processes enhanced synchronously.

\section{Conclusion}

The significance of lean thinking is obvious. In the specific implementation process, on the one hand, it requires a combination of corporate strategy and consideration of the plan; on the other hand, the new product development process reengineering is not a single enterprise activity, but also combined with various other aspects. The new product process reengineering based on lean thinking will be an effective way to add value in $\mathrm{R} \& \mathrm{D}$ and play a positive role in promoting.

\section{References:}

[1]Cai Zhiqing, foreign military research and production management business process reengineering case studies, Electronic Mechanical Engineering 2010 Volume 26 Issue 2.

[2]Yangzheng Wu, Modern business process reengineering innovative ideas, Business Times 2011 13.

[3]He Ling, Research and implementation of the research team knowledge management platform, South China University of Technology,2010.

[4]Information on http://www.cardiff.ac.uk/lean/principles/

[5]Information on http://en.wikipedia.org/wiki/Business_process_reengineering 